\title{
Stock Market Anomalies as Mediators Between Prospect Factors and Investment Decisions and Performance: Findings at the Individual Investor Level
}

\section{Syed Zain Ul Abdin, Naheed Sultana, Mariam Farooq, Syed Zulfiqar Ali Shah*}

\begin{abstract}
While other studies have investigated the direct impact of prospect factors on investment decisions and performance at the individual level, we examine the mediated link between the two, via fundamental, technical and calendar anomalies. The study applies a structural equation model to data for 324 individual investors in Pakistan. Our findings show that two processes, fundamental and calendar anomalies, mediate the relationship between certain prospect factors and investment decisions and performance. Of these prospect factors, regret aversion is the strongest predictor of investment decisions and performance, followed by calendar anomalies. It is also the strongest predictor of investment decisions and performance via fundamental anomalies.
\end{abstract}

Keywords: Prospect theory, stock market anomalies, investment decision and performance, behavioral finance.

JEL classification: G2, G14, G15.

\footnotetext{
* Lahore Business School, University of Lahore; assistant professor of management, Faculty of Management Sciences, University of Central Punjab, Lahore; associate professor of finance, Faculty of Management Sciences, International Islamic University, Islamabad. We are grateful to Muhammad Arshad and Fatima Haider for their assistance in the data analysis.
} 